\title{
\begin{tabular}{l|l|l}
\hline & Jurnal Kependidikan Dasar & $\begin{array}{l}\text { Volume. 2 } \\
\text { Nomor. 1 } \\
\text { Tahun. 2017 }\end{array}$ \\
\hline
\end{tabular}
}

\section{Analisis Psikologi Tokoh dalam Filosofi Kopi untuk Menentukan Materi Pembelajaran Sastra}

\author{
Ayunda Riska Puspita \\ IAIN Ponorogo \\ Email: ayunda.riska@gmail.com
}

\begin{abstract}
Abstrak
Karya sastra merupakan salah satu media untuk memotivasi siswa. Motivasi tersebut biasanya disampaikan dalam pesan yang terkandung dalam karya sastra. Salah satu pembawa pesan dalam karya sastra adalah melalui tokoh yang digambarkan oleh pengarang. Untuk mengetahui pesan yang terkandung dalam karya sastra melalui tokohnya, dapat dianalisis melalui psikologi tokoh dengan pendekatan psikoanalisa yang disampiakan oleh Freud. Psikoanalisa Freud menganalisis tiga unsur dalam diri manusi, yakni id, ego, dan super ego. Ketiga sistem tersebut bekerja secara seimbang pada diri Ben. Semula Ben dikuasai oleh id, dan ego selalu berjalan dengan id. Kemudian sedikit demi sedikit konflikkonflik yang dialami oleh Ben mengakibatkan ego tak sejalan lagi dengan id. Hal ini mengakibatkan superego muncul pada diri Ben, dan menjalankan fungsinya. Analisis ini berkontribusi dalam pembelajaran sastra, yakni kontribusi pada aspek afektif dan kognisi. Pada aspek afektif, analisis ini dapat memberi motivasi peserta didik agar menjadi manusia yang tidak ambisi dalam mengejar kesempurnaan karena tidak ada yang sempurna di dunia ini. Pada aspek kognitif, kajian ini dapat memberikan kontribusi untuk menambah pengetahuan mahasiswa tentang analisis karya sastra, khususnya cerpen.
\end{abstract}

Kata Kunci: Psikologi Tokoh, Psikoanalisa Sigmund Freud, Pembelajaran Sastra

\begin{abstract}
Literary works is one of the media to motivate students. Such motivation is usually conveyed in a message contained in a literary work. One of the messengers in literary works is through the characters portrayed by the author. To know the message contained in the literary works through the characters, can be analyzed through psychological figures with psychoanalytical approach that was delivered by Freud. Freud's psychoanalysis analyzes the three elements in man, id, ego, and super ego. All three of these systems work in balanced on Ben. Ben initially dominated by the id, and ego always line with id. Then little by little the conflicts experienced by Ben resulted in the ego not in line with the id. This results in the superego appearing in Ben, and performing its function. This analysis contributes to literary learning, which contributes to the affective and cognitive aspects. On the affective aspect, this analysis can motivate the learner to become a man who is not ambitious in chase of perfection because there is nothing perfect in this world. In the cognitive aspect, this analyzes can contribute to increase the students' knowledge about the analysis of literary works, especially short stories.
\end{abstract}




\section{A. PENDAHULUAN}

Pembelajaran Bahasa Indonesia di sekolah mulai dari tingkat dasar sampai dengan tingkat tinggi selalu berkaitan dengan pembelajaran kemapuan berbahasa dan bersastra. Perkembangan bahasa dan sastra di Indonesia berjalan saling beriringan. Keduanya mulai berkembang ketika bahasa Indonesia mulai diikrarkan di Sumpah Pemuda. Bahasa merupakan media karya sastra yang terpenting. Tanpa bahsa sastra tidak akan tersampaikan.

Karya sastra merupakan buah karya yang sarat akan gambaran-gambaran psikologi manusia. Tidak jarang karya sastra menggambarkan esensi psikologi manusia yang tidak disadari sebelumnya. Di sini, kita mengalami dimensi mengenai penentu perilaku yang bersifat tidak sadar. ${ }^{1}$

Psikologi yang terdapat pada karya sastra dapat ditinjau dari karya sastra itu sendiri atau dari pengarangnya. Secara langsung maupun tidak langsung pengarang selalu terlibat dalam psikologi yang terkandung dalam karyanya. Pengarang akan menangkap gejala jiwa kemudian diolah ke dalam teks dan dilengkapi dengan kejiwaan proyeksi pengalaman sendiri dan pengalaman hidup di sekitar pengarang, akan terproyeksi secara ima-

\footnotetext{
${ }^{1}$ Howard S. Friedman and Miriam W. Schustack, Kepribadian: Teori Klasik Dan Riset Modern (Jakarta: Erlangga, 2006), 20.
}

jiner ke dalam teks sastra. ${ }^{2}$

Kajian ini menganalisis cerpen karya Dee (nama populer dari Dewi Lestari) yang berjudul "Filosofi Kopi". Cerpen ini menguak tentang ambisi seorang laki-laki bernama Ben dalam mencari kesempurnaan pada rasa kopi yang ia buat. Ia ingin menjadi barista terbaik di Jakarta, bahkan di dunia. Semua usaha dia lakukan untuk meraih kesempurnaan itu. Ben tidak menyadari bahwa di dunia ini tidak ada yang sempurna, namun pada suatu ketika dia menemukan apa arti hidup yang di dalamnya memang tidak pernah ada kesempurnaan. Dari penggalan cerita tersebut dapat diketahui bagaimana gambaran singkat psikologi pada diri Ben. Jadi pada makalah ini, analisis cerpen "Filosofi Kopi" tersebut mengunakan pendekatan psikologi tokoh.

Cerpen "Filosofi Kopi" merupakan salah satu cerpen Dee yang mendapat penghargaan "Karya Sastra Terbaik 2006" pilihan Majalah Tempo, di samping cerpen-cerpennya yang lain yang terdapat pada bukunya yang berjudul "Filosofi Kopi, Kumpulan Cerita dan Prosa Satu Dekade (1995-2005)". Cerpen "Filosofi Kopi" tersebut dibuat tahun 1996. Saat itu adalah puncaknya Dee suka sekali dengan kopi. Dari situ, Dee mulai mereka-reka tokohnya. Sebenarnya, dari dulu Dee memang bercita-cita punya kafe. Jadi sebetulnya, keinginan Ben dalam cerpen

\footnotetext{
${ }^{2}$ Suwardi Endraswara, Metodologi Penelitian Karya Sastra, Epistimologi, Model, Teori, Dan Aplikasi (Yogyakarta: Pustaka Widyatama, 2003), 96.
} 
"Filosofi Kopi" itu adalah keinginan Dee. Semua itu bermula dari kesukaannya terhdap kopi.

Kajian ini merupakan kajian sastra dengan pendekatan psikologi sastra dan lebih spesifik lagi adalah pendekatan psikologi tokoh. Teori pendekatan yang digunakan adalah terori psikoanalisa yang dikembangkan oleh Sigmun Freud. Pendekatan psikoanalisa menganalisis komponen-komponen kepribadian pada seorang tokoh, yakni id, ego, dan superego. Selain psikoanalisa, pendekatan yang digunakan dalam analisis ini adalah pendekatan intertekstualitas. Menurut Teeuw (dalam Nurgiyantoro), intertekstual dimaksudkan sebagai kajian terhadap sejumlah teks (lengkapnya: teks kesastraan) yang diduga mempunyai bentukbentuk hubungan tertentu, misalnya untuk menemukan adanya hubungan unsurunsur intrisik seperti ide, gagasan, peristiwa, plot, penokohan, (gaya) bahasa, dan lain-lain di antara teks-teks yang dikaji. Kajian ini difokuskan pada psikologis tokoh utama dalam cerpen. ${ }^{3}$

Langkah-langkah dalam penelitian ini meliputi analisis psikologi tokoh Ben dalam cerpen FIlosofi Kopi kemudian dilanjutkan dengan menganalisis kontribusi hasil analisis psikologi tokoh untuk pembelajaran sastra. Pada tahap analisis dianalisis id, ego, dan superego pada tokoh utama, Ben. Kemudian pada tahap analisis kontribusi, dianalisis pesan dalam cerpen Filosofi Kopi yang disampaikan melalui tokoh Ben. Kemudian dianalisis kontribusinya jika digunakan sebagai materi ajar dalam pembelajaran sastra.

\footnotetext{
${ }^{3}$ Burhan Nurgiyantoro, Teori Pengkajian Fiksi (Gadjah Mada University Press, 1995), 50.
}

Penelitian serupa dengan kajian ini adalah penelitian Yuenti Sova Puspidalia ${ }^{4}$ yang mengkaji tentang analisis sastra menggunakan pendekatan strukturalisme dan intertekstualitas dengan menganalisis nilai etika, estetika, dan dinamika dalam dovel Roro Mendut dan Sam Pek Eng Tai. Dari kajian yang ditulis oleh Yuenti dapat disimpulkan bahwa novel RM dan SE memiliki nilai etika, estetika, dan dinamika yang dapat dijadikan materi pembelajaran analisis karya sastra. Pembelajaran analisis etika, estetika, dan dinamika sosial budaya dalam Novel $R M$ dan $S E$, dapat mengembangkan aspek kognitif, afektif, dan kepribadian mahasiswa. Tujuan analisis sastra yang dilakukan dalam penelitian ini memiliki kesamaan dengan penelitian yang dilkukan Yuenti, namun pendekatan yang dilakukan tidak sama. Dalam kajian ini, peneliti menggunakan pendekatan psikoanalisis yang dikemukakan oleh Sigmun Freud.

Penelitian selanjutnya adalah penelitian yang dilakukan oleh Matilda Angelina Inna. ${ }^{5}$ Matilda mengkaji sebuah roman yang berjudul Der Vorleser karya Bernhard Schlink. Matilda menggunakan pendekatan psikoanalisis Sigmun Freud. Matilda menganalisis id, ego, dan superego tokoh utama dalam roman tersebut.

\footnotetext{
${ }^{4}$ Yuentie Sova Puspidalia, "ETIKA, ESTETIKA, DAN DINAMIKA DALAM NOVEL RORO MENDUT DAN SAN PEK ENG TAY SERTA SUMBANGANNYA DALAM PEMBELAJARAN SASTRA DI PROGRAM STUDI PGMI STAIN PONOROGO," Cendekia: Jurnal Kependidikan Dan Kemasyarakatan 14, no. 2 (2016),

http://jurnal.stainponorogo.ac.id/index.php/cendekia/a rticle/view/681.

${ }^{5}$ Matilda Angelina Inna, "Kepribadian Tokoh Utama Michael Berg Dalam Roman Der Vorleser Karya Bernhard Schlink" (Universitas Negeri Yogyakarta, 2015).
} 
Selanjutnya, Matilda menganalisis implikasi karya analisis roman karya Bernhard Schlink tersebut sebagai bahan ajar. Penelitian yang dilakukan oleh Matilda tersebut memiliki kesamaan dengan kajian ini karena kajian ini juga menggunakan pendekatan psikoanalisa yang dikembangkan oleh Freud. Namun, karya sastr yang dijadikan objek penelitian tidak sama dannimplikasi untuk pembelajarannya juga tidak sama. Jika dalam penelitian Matilda terdahulu implikasinya terhadap pembelaaran sastra Jerman, dalam penelitian ini akan dianalisis implikasi gambaran tokoh utama untuk materi pembelajaran analisis sastra Indonesia.

Tujuan penelitian ini adalah utuk menentukan pemilihan materi ajar analisis karya sastra dengan melakukan analisis psikologi tokoh. Secara lebih rinci, penelitian ini bertujuan untuk (1) mendeskripsikan unsur $i d$, ego, dan superego tokoh utama (Ben) dalam cerpen Filosofi Kopi karya Dewi Lestari dan (2) Menganalisis kontribusi analisis psikologi tokoh utama terhadap pemilihan materi ajar analisis karya sastra pada tingkat perguruan tinggi.

\section{B. LANDASAN TEORI}

Menurut Atkinson (dalam Minerop), psikologi dan sastra adalah dua hal yang berbeda, akan tetapi psikologi dan sastra mempunyai hubungan yang sangat erat. Psikologi berasal dari kata Yunani psyche, yang berarti jiwa atau ilmu yang menyelidiki dan mempelajari tingkah laku manusia. ${ }^{6}$ Tingkah laku manusia inilah yang juga digambarkan dalam karya sastra

\footnotetext{
${ }^{6}$ Albertine Minderop, Metode karakterisasi telaah fiksi (Yayasan Pustaka Obor Indonesia, 2005).
}

oleh pengarangnya. Tingkah laku tokoh ini pulalah yang membawa pesan yang akan disampaikan pengarang dalam karyanya. Hubungan inilah yang menyebabkan adanya kajian psikologi dalam karya sastra.

Kajian psikologi sastra dibagi menjadi tiga pendekatan, yaitu: pendekatan tekstual yang mengkaji tentang aspek psiklogis tokoh dalam karya sastra. Kedua, pendekatan reseptif-pragmatig yang mengkaji aspek psikologis pembaca sebagai penikmat sastra. Ketiga, pendekatan ekspresif yang mengkaji psikologis sang penulis ketika melakukan proses kreatif. ${ }^{7}$

Wellek dan Warren mengemukakan bahwa psikologi sastra mempunyai empat kemungkinan penelitian. Pertama, penelitian terhadap psikologi pengarang sebagai tipe atau sebagai pribadi. Kedua, penelitian proses kreatif dalam kaitannya dengan kejiwaan. Ketiga, penelitian hukum-hukum psikologi yang diterapkan dalam karya sastra. Dalam kaitan ini, studi dapat diarahkan pada teori-teori psikologi, misalnya psikoanalisis ke dalam sebuah teks sastra. Asumsi dari kajian ini bahwa pengarang sering menggunakan teori psikologi tertentu dalam penciptaan. Studi ini yang benar-benar mengangkat teks sastra sebagai wilayah kajian. Keempat, penelitian dampak psikologis teks sastra kepada pembaca.

Menurut Endraswara, psikoanalisa adalah wilayah kajian psikologi sastra. Dalam psikologi kepribadian yang dikemukakan oleh Freud, psikoanalisa tersusun atas tiga sistem pokok, yakni id, ego, dan superego. Ketiga sistem tersebut masing-

\footnotetext{
${ }^{7}$ Rene Wellek and Austin Waren, Teori Kesusastraan (Jakarta: Gramedia, 1990), 90.
} 
masing memiliki fungsi, sifat, komponen, prinsip kerja, dinamisme, dan mekanisme sendiri, namun ketiga sistem tersebut berinteraksi secara erat satu sama lain, sehingga prinsip kerjanya tidak dapat dipisahkan satu sama lain. ${ }^{8}$

Sigmund Freud mengatakan secara tegas bahwa teori struktural kepribadian yang sangat terkenal terdiri atas id, ego, dan superego. Id terletak pada ketidaksadaran (unconsious mind), ego meliputi ketiga tingkat kesadaran manusia, yakni ketidaksadaran (unconsious mind), prasadar (pre consious mind) dan sadar (consious mind) dan superego terletak pada alam ketidaksadaran (unconscious mind) dan pra-sadar (pre consious mind) (Feist, 2010: 31). ${ }^{9}$ Perilaku manusia pada hakikatnya merupakan hasil interaksi ketiga unsur kepribadian manusia, id, ego, dan superego. Ketiga unsur tersebut selalu bekerja sehingga menghasilkan sikap yang wajar dan sesuai. Jika salah satu unsur tersebut tidak berfungsi, akan ada ketimpangan.

Freud juga menyampaikan bahwa id merupakan jembatan antara segi biologis dan psikis manusia, sehingga id bersifat primitif. Karena berisi dorongan primitif, id bersifat kaotik (kacau, tanpa aturan), tidak mengenal moral, tidak memiliki rasa benar - salah. Satu-satunya hal yang diketahui oleh id adalah perasaan senangtidak senang, sehingga id dikatakan bekerja berdasarkan prinsip kesenangan (pleasure principle). Id selalu mengejar kesenangan dan menghindari ketegangan.

\footnotetext{
${ }^{8}$ Endraswara, Metodologi Penelitian Karya Sastra, Epistimologi, Model, Teori, Dan Aplikasi, 101.

9 Jess Feist and Gregory J. Feist, "Teori Kepribadian," Jakarta: Salemba Humanika, 2010, 31.
}

Apabila dorongan-dorongan yang ada pada id tersebut terpenuhi dengan segera maka akan menimbulkan rasa senang, puas serta gembira. Sebaliknya apabila tidak dipenuhi atau dilaksanakan dengan segera maka akan terjadi hal yang sebaliknya. ${ }^{10}$

Berlawanan dengan id yang bekerja berdasarkan prinsip kesenangan, ego bekerja berdasarkan prinsip realitas (reality principle). Hal ini berarti ia dapat menunda pemuasan diri atau mencari bentuk pemuasan lain yang lebih sesuai dengan batasan lingkungan (fisik maupun sosial) dan hati nurani. Ego menjalankan proses sekunder (secondary process), artinya ia menggunakan kemampuan berpikir secara rasional dalam mencari pemecahan masalah terbaik. ${ }^{11}$

Superego adalah sistem kepribadian ketiga dalam diri seseorang yang berisi kata hati (conscience). Kata hati ini berhubungan dengan lingkungan sosial dan memiliki nilai-nilai aturan dan normanorma dalam masyarakat sehingga merupakan kontrol atau sensor terhadap dorongan-dorongan yang datang dari id. Superego menghendaki agar dorongandorongan tertentu saja dari id yang direalisasikan, sedangkan dorongan-dorongan yang tidak sesuai dengan nilai-nilai moral agar tetap tidak dipenuhi.12 Superego bersifat non rasional dalam menuntut kesempurnaan, menghukum dengan kesalahan ego, baik yang telah dilakukan maupun baru dalam pikiran. Ada 3 fungsi

\footnotetext{
${ }^{10}$ Budi S. S. Hartono, “Dasar-Dasar Psikoanalisis Freudian" Dalam Psikoanalisis Dan Sastra (Depok: Pusat Penelitian Kemasyarakatan dan Budaya Lembaga Penelitian Universitas Indonesia, 2003), 3. ${ }^{11}$ Ibid., 4.

${ }^{12}$ Singgih Dirgagunarsa, Pengantar Psikologi (Mutiara, 1978), 64.
} 
dari superego; (1) mendorong ego menggantikan tujuan-tujuan realistik dengan tujuan-tujuan moralistis, (2) memerintah impuls Id, terutama impuls seksual dan agresif yang bertentangan dengan standart nilai masyarakat, dan (3) mengejar kesempurnaan. ${ }^{13}$

Id merupakan sistem kepribadian manusia yang paling dasar. Prinsip kerja id disebut prinsip kenikmatan (pleasure principle). Gambaran-gambaran mentah yang bersifat memenuhi hasrat merupakan satu-satunya kenyataan yang dikenal id. Ego merupakan bagian dari kepribadian manusia yang langsung mangalami realitas. Prinsip kerja ego mengikuti prinsip kenyataan. Ego merupakan penengah antara id dan superego. Superego adalah wewenag moral dari kepribadian. Perhatiannya yang utama adalah memutuskan apakah sesuatu itu benar atau salah, dengan demikian seseorang dapat bertindak sesuai dengan norma-norma moral yang diakui oleh masyarakat. ${ }^{14}$

\section{PEMBAHASAN}

\section{Analisis Cerpen "Filosofi Kopi" dengan Pendekatan Psikologi Tokoh}

Cerpen "Filosofi Kopi" memiliki tema yang unik, yaitu cinta yang begitu mendalam dari seorang barista kepada kopi. Ini merupakan hal yang tidak biasa karena pada umumnya cerita yang bertema cinta selalu mengisahkan cinta antarmanusia. Kecintaannya terhadap kopi membuatnya mengesampingkan segala hal. Kopi sangat berarti dalam hidupnya.

${ }^{13}$ Calvin S. Hall and Gardner Lindzey, Teori- Teori Psikodinamik (Klinis) (Yogyakarta: Kanisius, 1993), 67-68.

${ }^{14}$ Ibid., 64-68.
"Ben bangkit berdiri. 'Memang cuma duit yang kamu pikir! Profit, laba, omset,... kamu memang tidak pernah mengerti arti kopi buatku. Ambil saja Filosofi Kopi. Kamu sama dengan laki-laki goblok sok sukses itu..."'. .15

Cerpen ini menyampaikan pesan kehidupan melalui cerita kopi-kopi yang diracik oleh Ben, sang barista. Setiap kopi memiliki filosofinya masing-masing, seperti capuccino yang katanya adalah kopi bercita rasa paling tinggi yang penuh keindahan, dan berbagai jenis kopi lain dengan filosofinya yang menarik. Pesan yang ingin disampaikan melalui kopi ini lebih ke tentang kehidupan, bagaimana kehidupan yang kita inginkan, sesuai dengan kopi favorit kita.

"Tak sampai di situ, Ben juga membuat kartu kecil yang dibagikan kepada setiap orang sehabis berkunjung. Kartu itu bertuliskan: 'KOPI YANG ANDA MINUM HARI INI: ... ' dan keterangan filosofinya". 16

Cerpen "Filosofi Kopi” menggunakan sudut pandang orang ketiga. Jody, sahabat tokoh utama menjadi pencerita dalam cerpen tersebut. Dia menceritakan perjalanan Ben (tokoh utama dalam cerpen tersebut) dalam mewujudkan ambisinya menjadi barista dengan racikan kopinya yang sangat sempurna. Ambisi inilah yang selalu membuatnya berusaha keras untuk menjadi yang paling sempurna, dan tanpa dia sadari bahwa di dunia ini tidak ada yang sempurna. Dalam waktu tertentu Dee membuat kejutan dengan tiba-tiba hadir

\footnotetext{
${ }^{15}$ Dewi Lestari, Filosofi Kopi, Kumpulan Cerita Dan Prosa Satu Dekade (Jakarta: Truedee Books dan Gagas Media, 2010), 24.

${ }^{16}$ Ibid., 7.
} 
dalam cerita. Kehadirannya dalam cerpennya tersebut berperan sebagai pencerita. Dia menarasikan tokoh Jody.

Dee menggunakan alur yang terus maju, mengikuti cerita ambisi Ben dalam menemukan kesempurnaan dalam kopi yang dia racik. Penceritaan ambisi Ben tersebut dimulai dari perjalanan Ben ke berbagai negera untuk belajar tentang kopi. Kemudian Ben ditemani Jody mendirikan sebuah kedai kopi. Jody tidak tahu menahu tentang kopi, jadi dia menyumbangkan semua uang tabungan dan ilmu administrasinya untuk kedai mereka. Ben selalu menginginkan kesempurnaan dalam kopinya. Pada suatu ketika ada yang mengatakan bahwa kopinya tidak lebih enak dari pada kopi tiwus buatan Pak Seno. Ben merasa tertantang dan membuktikan sendiri bagaimana rasa kopi tiwus tersebut. Dari rasa yang begitu nikmat dan kerendahan hati Pak Seno, Ben menyadari bahwa di dunia ini memang tidak ada yang sempurna.

Ambisi Ben tidak terbatas pada kesempurnaan rasa kopi yang dibuatnya saja. Ben juga menginginkan kesempurnaan pada segala sesuatu yang berhubungan dengan kopi. Salah satu yang mendapat perhatiannya untuk melengkapi kesempurnaan tersebut adalah pada susunan tempat di kedai kopinya. Penataan kedai kopi Ben dan Jody sangat diperhitungkan oleh Ben. Untuk memilih perabot kedai mereka, Ben sangat memper timbangkan bagaimana keserasiannya dengan suasana minum kopi. Kedai kopi inilah yang sebagian besar menjadi setting tempat pada cerpen "Filosofi Kopi"

"Tempat kami tidak besar dan sederhana dibandingkan kafe-kafe lain di Jakarta. Namun di sini, setiap inci dipersiapkan dengan intensitas. Ben memilih setiap kursi dan mejasemuanya berbeda-dengan mengetesnya satu-satu, paling tidak seperempat jam per barang. Ia mencobanya sambil menghirup kopi, dan merasa-rasa dengan instingnya, apakah furniture itu cukup 'sejiwa' dengan pengalaman minum kopi. Begitu juga dengan gelas, cangkr, bush kettle, poci, dan lain-lain. Tidak ada yang tidak melalui tes kompatibilitas Ben terlebih dulu. Dengn ia menjadi pusat, dikelilingi mereka yang duduk di susunan rapat meja-kursi beraneka model, aku seolah menyaksikan sebuah perhelatan pribadi. Pesta minum kopi, kecil dan akrab, dengan Ben sebagai tuan rumah". ${ }^{17}$

Dalam teori psikologi kepribadian Freud, disebutkan bahwa orang yang normal, dalam hidupnya pasti mengalami ketiga sistem yang dikemukakan oleh Freud yaitu id, ego, dan superego. Ketiga sistem tersebut bekerja sama dan saling berhubungan satu sama lain. Demikian halnya dengan Ben yang merupakan manusia normal. Ben juga mengalami ketiga sistem tersebut dalam dirinya.

Ambisi Ben yang begitu keras ini menunjukkan bahwa diri Ben dikuasai oleh id. Ben adalah seorang penggila kopi, dia terobsesi oleh kenikmatan kopi. Obsesi itu membawanya menjadi seorang barista. Kedai kopi yang dia dirikan bersama Jody bukan kedai kopi biasa, namun "Kedai Koffie Ben \& Jody" yang idealis dan berkelas. Kedai kopi yang menawarkan racikan dan pengalaman ngopi tidak terlupakan. Ben tidak sekedar meramu, mengecap rasa, tapi juga merenungkan kopi yang ia buat. Ben menarik arti,

\footnotetext{
${ }^{17}$ Ibid., 3.
} 
membuat analogi, hingga terciptalah satu filosofi untuk setiap jenis ramuan kopi.

"Tapi yang benar-benar membuat tempat itu istimewa adalah pengalaman ngopi-ngopi yang diciptakan Ben. Ia tidak sekedar meramu, mengecap rasa, tapi juga merenungkan kopi yang ia buat. Ben menarik arti, membuat analogi, hingga terciptalah satu filosofi untuk setiap jenis ramuan kopi”. ${ }^{18}$

Seiring berjalannya cerita yang terus menghadirkan kisah-kisah Ben dengan filosofi-filosofi yang dia sajikan dalam setiap kopinya, semua ambisi dan obsesi Ben terus saja terwujud. Ben selalu menemukan hal-hal yang baru dari kopi yang dia ramu dengan filosofinya yang sangat menarik. Penggemar kopi banyak yang datang dan menjadi pelanggan tetap di kedai Ben, bahkan banyak orang yang hanya sekedar ingin tahu mampir untuk mencicipi kopi dengan filosofi yang dibuat oleh Ben. Ini menunjukkan ego berjalan mengikuti $i d$.

"Nama kedai kami berikut slogannya ternyata menjadi sangat popular. Kuamati semakin banyak orang yang berhenti, membaca, kemudian dengan wajah ingin tahu mereka masuk ke dalam, waswas sekaligus harap-harap cemas, seperti memasuki tenda peramal. Dan tanpa perlu bola kristal, omset kedai kami meningkat pesat". ${ }^{19}$

Obsesinya untuk menciptakan ramuan terbaik dengan filosofi-filosofi baru terus berkembang. Hingga suatu ketika datang seorang berduit yang menantangnya membuat racikan kopi sempurna. Taruhannya selembar cek bernilai 50 juta rupiah. Lalu Ben menjadi

\footnotetext{
18 Ibid., 4.

${ }^{19}$ Ibid., 7.
}

"gila". Dan seperti seorang profesor di laboratoriumnya, dia bereksperimen menciptakan ramuan-ramuan kopi untuk melahirkan "kopi sempurna" bernilai 50 juta rupiah. Kerja kerasnya membuahkan hasil. Kopi temuannya yang baru ini dinamakan "Ben's Perfecto".

"Disaksikan semua pelanggan yang sengaja kami undang. Ben menyuguhkan secangkir Ben's Perfecto pertamanya dengan raut tegang.

Pria itu menyeruput, menahan napas, kemudian mengembuskannya lagi sambil berkata perlahan, 'Hidup ini sempurna.'

Kedai mungil kami gegap gempita. Semua orang bersorak.

Pria itu mengeluarkan selembar cek. 'Selamat. Kopi ini perfect. Sempurna.'”. ${ }^{20}$

Penceritaan Dee yang kreatif membuat cerpen ini tidak terkesan monoton karena sepanjang cerita pada cerpen ini tidak selamanya ego berjalan sesuai dengan id. Adakalanya ego berjalan melawan id. Setelah ditemukannya "Ben's Perfecto", ternyata kesuksesan Ben bukanlah klimaks dari cerpen ini. Karena selang beberapa waktu datang seorang tamu yang membuat Ben hilang kesabaran. Pasalnya, tamu itu begitu biasa menanggapi kopi paling perfect yang pernah diracik oleh Ben. Tamu tersebut mengatakan bahwa kopi yang paling sempurna tersebut masih kalah dengan kopi tiwus buatan Pak Seno.

"Dengan ekspresi sopan, bapak itu mengangguk-angguk, 'Lumayan,' jawabnya singkat lalu terus membaca.

'Lumayan bagaimana?' Ben mulai terusik.

'Ya, maksudnya lumayan enak toh, Dik,' ia membalas.

\footnotetext{
${ }^{20}$ Ibid., 13.
} 
'Pak, yang barusan Bapak minum itu kopi yang paling enak di dunia.' Aku tidak tahan untuk tidak menjelaskan.

'Yang bener toh? Masa iya?' Seperti mendengar lelucon bapak itu malah tertawa kecil". 21

Dalam keadaan yang seperti itu, ambisi Ben tetap saja sangat kuat. Diri Ben masih dikuasai oleh id. Ben mencari Pak Seno untuk membuktikan kebenaran rasa kopi tiwus yang dikatakan oleh tamunya tersebut. Ben rela melakukan perjalanan jauh dan melewati medan yang terjal menuju daerah Klaten-Jawa Tengah untuk mencari apa yang dia mau. Ben memutuskan melakukan perjalanan itu dalam keadaan marah. Hingga akhirnya dia menemukan warung Pak Seno yang sudah reot. Di sana dia meneguk kopi yang dibuat oleh Pak Seno.

"Ben seperti kerasukan setan. Jalanan becek dan berlubang itu dilewatinya dengan kecepatan jalan tol. Tinggallah aku yang sekuat tenaga menahan mual.

Tepat di penghujung jalan, sebuah warung reot dan gubug berdiri di atas bukit kecil, ternaungi pepohonan besar. Di halamannya terdapat tampitampi berisi biji kopi yang baru dipetik. Di sekitar gubug itu terdapat tanamantanaman perdu dengan bunga-bunga ptih yang semarak bermunculan di sana sini. Aku baru tersadar, seluruh bukit kecil itu ditanami tanaman kopi". ${ }^{22}$

Setelah pertemuannya dengan Pak Seno, dan merasakan sendiri kopi yang diracik oleh Pak Seno, Ben mulai menyadari bahwa di dunia ini tidak ada yang sempurna. "Ben's Perfecto", kopi buatan Ben yang dianggapnya paling sempurna

\footnotetext{
${ }^{21}$ Ibid., 16.

${ }^{22}$ Ibid., 19-20.
}

adalah sebuah hal yang sangat memalukan. Apalagi setelah dia bertemu dan berbincang-bincang dengan Pak Seno, sosok seorang bapak yang sangat rendah hati, padahal kopi yang dibuatnya sangat nikmat. Di sinilah superego pada diri Ben mulai menunjukkan perannya, yaitu mengembalikan Ben pada norma yang berlaku di masyarakat. Id yang semula dominan menjadi seimbang dengan sistem yang lain. Ben sangat malu pada dirinya sendiri dan Pak Seno, sampai-sampai dia tidak mau meramu kopi lagi dan bertengkar dengan Jody sahabatnya sendiri. Dalam hal ini Pak Seno berperan sebagai pemancing munculnya superego yang selama cerita berjalan jarang ditemukan pada diri Ben, bahkan tidak ada sama sekali.

“Kamu masih tidak sadar?' Ben manatapku prihatin. 'Aku sudah diperalat oleh seseorang yang merasa punya segala-galanya, menjebakku dalam tantangan bodoh yang cuma jadi pemuas egonya saja, dan aku sendiri terperangkap dalam kesempurnaan palsu, artificial!' serunya gemas, 'Aku malu pada diriku sendiri, pada semua orang yang sudah kujejali dengan kegombalan Ben's Perfecto."'.23

Demikianlah ketiga sistem tersebut bekerja pada diri Ben. Pada awalnya ketiga sistem tersebut tidak seimbang. Ada salah satu yang mendominasi diri Ben, yaitu id, dan ego sebagian besar mengikuti id. Di penghujung cerita, baru superego mulai menunjukkan perannya. Dengan hadirnya superego pada diri Ben maka ketiga sistem yang dikemukakan oleh Freud bekerja secara berimbang dan saling mempengaruhi.

\footnotetext{
${ }^{23}$ Ibid., 23.
} 


\section{Kontribusi Kajian Psikoanalisis Tokoh dalam Pembelajaran Sastra}

Seorang guru seringkali berperan sebagai seorang motivator, seorang sumber informasi, seorang pemandu aktivitas pembelajaran, dan juga sebagai seorang penguji. ${ }^{24}$ Sebagai seorang motivator, sumber informasi, dan pemandu aktivitas, seorang guru/dosen dituntut untuk memilih materi pembelajaran yang berisi informasi yang dapat memberi motivasi kepada peserta didik agar menjadi lebih baik, seperti tujuan dalam pendidikan. Demikian juga dengan pembelajaran sastra. Dalam mpelaksanaan pembelajaran sastra seorang guru maupun dosen juga harus dapat memilih materi yang tepat yang dapat memotivasi peserta didik.

Salah satu pemelihan materi yang dapat memotivasi peseta didik untuk menjadi lebih baik adalah melalui pembelajaran sastra, khususnya cerpen, karena karya sastra selalu mengusung pesan moral yang baik. Dengan pemilihan materi yang tepat, seorang guru/dosen akan dapat memotivasi peserta didik untuk menjadi pribadi yang lebih baik. Motivasi dengan pemilihan bahan ajar biasanya dapat melalui karya sastra itu sendiri. Motivasi dapat diperoleh dari pesan yang disampikan oleh pengarang melalui karyanya.

Karya fiksi/sastra ditulis pengarang untuk menawarkan kehidupan yang diidealkannya. Melalui cerita, sikap, dan tingkah laku tokoh dalam cerita, pembaca diharapkan dapat mengabil hikmah dan

\footnotetext{
${ }^{24}$ Hairuddin et al., "Pembelajaran Bahasa Indonesia" (Jakarta: Direktorat Jendral Pendidikan Tinggi Departemen Pendidikan Nasional., 2007).
}

pesan-pesan moral yang disampaikan atau diamanatkan dalam karya sastra (Nurgiyantoro, 2013:430). Dari hasil analisis psikologi tokoh pada bagian sebelumnya, dapat dianalisis pesan moral yang terkandung dalam cerpen Filosofi Kopi karangan Dewi Lestari karena salah satu pembawa pesan dalam karya sastra adalah tokoh yang ada di dalamnya.

Berdasarkan analisis psikologi tokoh Ben, pesan moral yang terkandung dalam cerpen Filosofi Kopi adalah tentang kesempurnaan hidup. Melalui tokoh Ben, Dewi Lestari ingin menyampaikan bahwa di dunia ini tidak akan pernah ada kesempurnaan, sejauh apapun kita mencarinya. Sesuatu yang kita anggap sempurna, pasti akan ada yang lebih sempurna. Hal ini ditunjukkan ketika superego dalam diri Ben sudah menunjukkan perannya, yakni ketika Ben menyadari bahwa kopi yang dibuatnya dianggap paling sempurna ternyata masih kalah nikmatnya dengan kopi tiwus Pak Seno yang sederhana dan rendah hati. Meskipun rasa kopinya sangat nikmat, Pak Seno tidak pernah sesombong Ben. Pak Seno juga bukan seorang yang ambisius seperti Ben.

Dengan demikian, analisis tokoh Ben dalam cerpen Filosofi Kopi ini berkontribusi sebagai media memotivasi peserta didik agar menjadi manusia yang tidak ambisi dalam mengejar kesempurnaan karena tidak ada yang sempurna di dunia ini. Kontribusi yang disampaikan melalui pesan cerpen Filosofi Kopi tersebut merupakan kontribusi dalam pembejalaran, khususnya pada aspek afektif. Dengan menggunakan cerpen Filosofi Kopi dalam pembelajaran sastra, peserta diha- 
rapkan dapat mengambil pelajaran dari tokoh Ben, sehingga dapat tertanam sifat rendah hati dan tidak berambisi mengejar kesempurnaan, tapi menjalani dengan penuh keikhlasan. Hal ini juga ditujukkan dalam filosofi kopi tiwus yang diberikan Jody kepada Ben di akhir cerita, yakni "Walau tak ada yang sempurna, hidup ini indah begini adanya".

Dari aspek kognitif, penelitian ini memberikan kontribusi pengetahuanpengetahuan kepada mahasiswa. Pengetahuan yang diperoleh mahasiswa adalah pengetahuan tentang analisis karya sastra, khususnya cerpen. Analisis karya sastra memiliki banyak pendekatan. Mahasiswa tidak hanya dapat menganalisis karya sastra secara objektif (unsur pembangun karya sastra) seperti yang dilakukan anak SMA pada umumnya. Mahasiswa dapat menganalisis karya sastra dengan pendekatan psikologi tokoh (mskipun masih ada pendekatan yang lain, seperti sosiologi sastra). Dalam analisis karya sastra menggunakan pendekatan psikologi tokoh, mahasiswa mendapat pengetahuan baru bahwa dalam diri seorang tokoh terdapat tiga sistem yang saling bekerja sama yakni id, ego, dan supergo, seperti yang dikemukaan oleh Freud.

\section{PENUTUP}

Cerpen "Filosofi Kopi" karya Dee merupakan cerpen yang sangat menarik. Mulai dari tema hingga cara bercerita Dee yang kreatif membuat cerpen ini sangat indah. Banyak kejutan dihadirkan oleh Dee pada cerpen ini yang tidak disangka sebelumnya oleh pembaca. Misalnya saja siapa yang akan menyangka bila akhirnya cek senilai 50 juta itu hanya disimpan di dalam almari bersama dengan tumpukan baju dan dijadikan kenang-kenangan oleh keluarga Pak Seno.

Sistem kepribadian yang disampaikan oleh Freud tidak serta merta disampaikan secara monoton. Ketiga sistem seperti yang dikemukakan oleh Feud, yaitu id, ego, dan superego bekerja secara seimbang pada diri Ben. Semua sistem itu saling berpengaruh satu sama lain. Semula Ben dikuasai oleh id, dan ego selalu berjalan dengan id. Kemudian sedikit demi sedikit konflik-konflik yang dialami oleh Ben mengakibatkan ego tak sejalan lagi dengan id. Hal ini mengakibatkan superego muncul pada diri Ben, dan menjalankan fungsinya. Proses kerjanya beruntut, hingga semuanya menjadi seimbang di akhir cerita.

Berdasarkan analisis psikologi tokoh pada cerpen Filosofi Kopi, dapat dismpulkan bahwa penelitian ini dapat memberikan kontribusi terhadap pembelajaran sastra. Kontribusi dalam pembelajaran dapat dilihat dari kontribusi dalam kemampuan afektif dan kognitif. Pada aspek afektif, analisis ini dapat memberi motivasi peserta didik agar menjadi manusia yang tidak ambisi dalam mengejar kesempurnaan karena tidak ada yang sempurna di dunia ini. Pada aspek kognitif, kajian ini dapat memberikan kontribusi untuk meambah pengetahuan mahasiswa. Pengetahuan yang diperoleh mahasiswa adalah pengetahuan tentang analisis karya sastra, khususnya cerpen.

Penelitian ini masih memerlukan kajian yang lebih dalam dan dapat dikembangkan dengan pendekatan yang lain 
untuk mendapatkan hasil analisis yang lebih mendalam. Peneliti selanjutnya bisa menggunakan pendekatan psikologi dengan fokus yang berbeda dari kajian ini. Peneliti selanjutnya dapat menggunakan pendekatan psikologi pengarang ataupun pembaca. Selain itu untuk memilih materi pembelajaran cerpen yang dapat menganalisis cerpen dengan pendekatan yang lain sebelum dijadikan materi.

\section{E. DAFTAR PUSTAKA}

Dirgagunarsa, Singgih. Pengantar Psikologi. Mutiara, 1978.

Endraswara, Suwardi. Metodologi Penelitian Karya Sastra, Epistimologi, Model, Teori, Dan Aplikasi. Yogyakarta: Pustaka Widyatama, 2003.

Feist, Jess, and Gregory J. Feist. "Teori Kepribadian." Jakarta: Salemba Humanika, 2010.

Friedman, Howard S., and Miriam W. Schustack. Kepribadian: Teori Klasik Dan Riset Modern. Jakarta: Erlangga, 2006.

Hairuddin, Linda Puspita, Soni Mirizon, and Zahra A. "Pembelajaran Bahasa Indonesia." Jakarta: Direktorat Jendral Pendidikan Tinggi Departemen Pendidikan Nasional., 2007.

Hall, Calvin S., and Gardner Lindzey. TeoriTeori Psikodinamik (Klinis). Yogyakarta: Kanisius, 1993.

Hartono, Budi S. S. "Dasar-Dasar Psikoanalisis Freudian" Dalam
Psikoanalisis Dan Sastra. Depok: Pusat Penelitian Kemasyarakatan dan Budaya Lembaga Penelitian Universitas Indonesia, 2003.

Inna, Matilda Angelina. "Kepribadian Tokoh Utama Michael Berg Dalam Roman Der Vorleser Karya Bernhard Schlink." Universitas Negeri Yogyakarta, 2015.

Lestari, Dewi. Filosofi Kopi, Kumpulan Cerita Dan Prosa Satu Dekade. Jakarta: Truedee Books dan Gagas Media, 2010.

Minderop, Albertine. Metode karakterisasi telaah fiksi. Yayasan Pustaka Obor Indonesia, 2005.

Nurgiyantoro, Burhan. Teori Pengkajian Fiksi. Gadjah Mada University Press, 1995.

Puspidalia, Yuentie Sova. "ETIKA, ESTETIKA, DAN DINAMIKA DALAM NOVEL RORO MENDUT DAN SAN PEK ENG TAY SERTA SUMBANGANNYA DALAM PEMBELAJARAN SASTRA DI PROGRAM STUDI PGMI STAIN PONOROGO." Cendekia: Jurnal Kependidikan Dan Kemasyarakatan 14, no. 2 (2016). http://jurnal.stainponorogo.ac.id/i ndex.php/cendekia/article/view/6 81.

Wellek, Rene, and Austin Waren. Teori Kesusastraan. Jakarta: Gramedia, 1990. 